\title{
In Vivo Glucosamine Infusion Induces Insulin Resistance in Normoglycemic but Not in Hyperglycemic Conscious Rats
}

Luciano Rossetti, Meredith Hawkins, Wei Chen, Jeffrey Gindi, and Nir Barzilai

Division of Endocrinology and Diabetes Research and Training Center, Albert Einstein College of Medicine, New York 10461

\begin{abstract}
To test the hypothesis that increased flux through the hexosamine biosynthetic pathway can induce insulin resistance in skeletal muscle in vivo, we monitored glucose uptake, glycolysis, and glycogen synthesis during insulin clamp studies in 6-h fasted conscious rats in the presence of a sustained (7-h) increase in glucosamine (GlcN) availability. Euglycemic $(\sim 7 \mathrm{mM})$ insulin $(\sim 2,500 \mathrm{pM})$ clamps with saline or GlcN infusions were performed in control (CON; plasma glucose $[P G]=7.4 \pm 0.2 \mathrm{mM})$, diabetic $(D ; P G=19.7 \pm 1.1)$, and phlorizin-treated (3-wk) diabetic rats (D + PHL; PG $=7.6 \pm 0.9)$. 7-h euglycemic hyperinsulinemia with saline did not significantly decrease $R_{\mathrm{d}}(360-420 \mathrm{~min}=39.2 \pm 3.6$ vs. 60-120 $\mathrm{min}=42.2 \pm 3.7 \mathrm{mg} / \mathrm{kg} \cdot \mathrm{min} ; P=\mathrm{NS})$. GlcN infusion raised plasma GlcN concentrations to $\sim 1.2 \mathrm{mM}$ and increased muscle and liver UDP-GlcNAc levels by 4 5-fold in all groups. GlcN markedly decreased $R_{\mathrm{d}}$ in CON $(360-420 \mathrm{~min}=30.4 \pm 1.3$ vs. $60-120 \mathrm{~min}=44.1 \pm 3.5 \mathrm{mg} /$ kg.min; $P<0.01)$ and D + PHL (360-420 $\mathrm{min}=29.4 \pm 2.5$ vs. $60-120 \mathrm{~min}=43.8 \pm 2.9 \mathrm{mg} / \mathrm{kg} \cdot \mathrm{min} ; P<0.01)$, but not in $D(5-7 \mathrm{~h}=21.5 \pm 0.8 \mathrm{vs} .0-2 \mathrm{~h}=24.3 \pm 1.1 \mathrm{mg} / \mathrm{kg} \cdot \mathrm{min}$; $P=\mathrm{NS})$. Thus, increased GlcN availability induces severe skeletal muscle insulin resistance in normoglycemic but not in chronically hyperglycemic rats. The lack of additive effects of GlcN and chronic hyperglycemia (experimental diabetes) provides support for the hypothesis that increased flux through the GlcN pathway in skeletal muscle may play an important role in glucose-induced insulin resistance in vivo. (J. Clin. Invest. 1995. 96:132-140.) Key words: glucosamine $\bullet$ insulin resistance $\cdot$ glycogen synthesis $\cdot$ glucose uptake $\cdot$ hyperglycemia
\end{abstract}

\section{Introduction}

The impairment in the ability of insulin to promote skeletal muscle glucose uptake is a common characteristic of non-insulin-dependent diabetes mellitus $(1-3)$ and poorly controlled insulin-dependent diabetes mellitus $(4,5)$. We and others sug-

This work was presented in preliminary form at the 54th annual meeting of the American Diabetes Association, New Orleans, 14-16 June 1994.

Address correspondence to Luciano Rossetti, M.D., Division of Endocrinology, Department of Medicine, Albert Einstein College of Medicine, 1300 Morris Park Avenue, Bronx, NY 10461. Phone: 718-4302192; FAX: 718-829-6988.

Received for publication 9 December 1994 and accepted in revised form 22 February 1995.

J. Clin. Invest.

(C) The American Society for Clinical Investigation, Inc.

0021-9738/95/07/0132/09 \$2.00

Volume 96, July 1995, 132-140 gested that some of the similar features of most insulin-resistant syndromes, regardless of their primary cause, may be due to the deleterious effects of chronic hyperglycemia per se on insulin action, in particular on skeletal muscle glucose transport (6-11). Defective insulin stimulation of the glucose transport system is the major cellular manifestation of prolonged hyperglycemia in insulin-sensitive tissues and defects in either or both glucose transporters' translocation and/or "intrinsic activity' may be involved (8-13).

Using primary cultures of adipose cells, Marshall et al. (1417) proposed that the downregulation of the glucose transport system observed after prolonged incubation with high insulin and glucose required the metabolism of hexose-phosphates in a quantitatively minor pathway of intracellular glucose utilization, i.e., the glucosamine $(\mathrm{GlcN})^{1}$ pathway (Fig. 1) which is initiated by the conversion of fructose-6-phosphate to GlcN-6-phosphate by the enzyme glutamine:fructose-6-phosphate amidotransferase (GFAT). They first showed that insulin had a permissive effect on glucose-induced desensitization which was independent of changes in insulin receptor binding $(18,19)$. The authors suggested that it may act by promoting glucose uptake and metabolism and that the latter was indispensable for the development of glucose-induced desensitization. The potential role of the hexosamine biosynthesis pathway was suggested by the observation that, in addition to glucose and insulin, the amino acid glutamine, which is needed for GFAT activity, was also required for the onset of desensitization in primary culture of adipose cells (20). Strong evidence for this "hexosamine hypothesis" was provided by experiments inducing desensitization of the glucose transport system after prolonged incubations with GlcN in the absence of high glucose and the prevention of the desensitization in the presence of glucose and insulin by the inhibition of GFAT (14). Further experimental support for this hypothesis comes from recent studies indicating that GlcN induces insulin resistance in isolated rat muscle (21) and may modulate insulin's and/or glucose's effects on pyruvate kinase $(22)$, glycogen synthase $(21,23)$, and transforming growth factor- $\alpha$ (24). Thus, in these isolated cell systems, the hyperactivity of the hexosamine biosynthetic pathway per se caused and its inhibition prevented the development of desensitization of the glucose transport system.

Whether this regulatory system is operating in the skeletal muscle of intact animals is not known. We therefore aimed to investigate whether the hexosamine biosynthetic pathway may function as a regulatory pathway capable of desensitizing the glucose transport system to insulin in skeletal muscle in vivo. We examined whether the glucose-induced desensitization of

1. Abbreviations used in this paper: GFAT, glutamine:fructose-6-phosphate amidotransferase; GlcN, glucosamine; UDP-Gal, uridinediphosphogalactose; UDP-GalNAc, UDP- $\boldsymbol{n}$-acetylgalactosamine; UDP-Glc, uridinediphosphoglucose; UDP-GlcNAc, UDP- $n$-acetylglucosamine. 


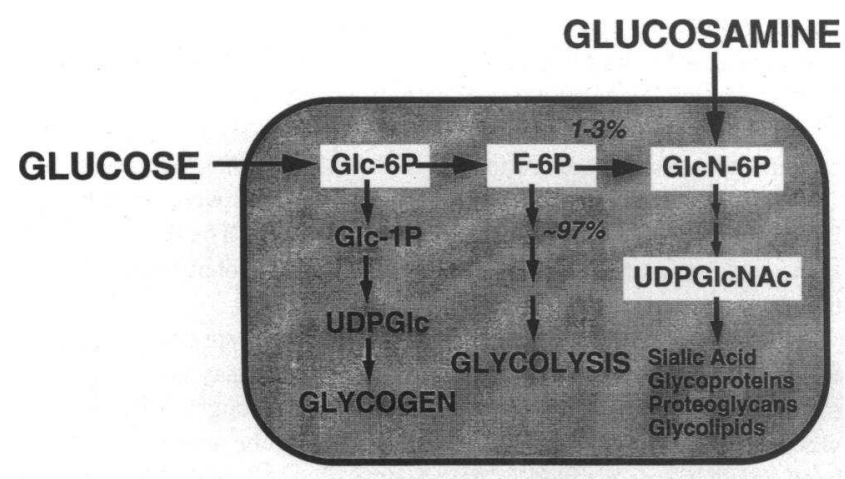

Figure 1. Schematic representation of the common steps in the intracellular metabolism of glucose and glucosamine. In skeletal muscle and adipose cells, glucose enters the cells through the action of glucose transporters (mostly GLUT4 in the presence of insulin) and is then rapidly phosphorylated to glucose-6-phosphate by the action of low $K_{\mathrm{m}}$ hexokinases. The great majority of glucose-6-phosphate is metabolized through glycogen synthesis, glycolysis, and pentose phosphate shunt (not shown). However, $\sim 1-3 \%$ of the incoming glucose is used for the formation of glucosamine-6-phosphate via the action of the enzyme glutamine:fructose-6-phosphate amidotransferase. Glucosamine is also transported via the glucose transporter system and then directly enters the hexosamine biosynthetic pathway at the level of glucosamine-6phosphate. Further metabolism of glucosamine-6-phosphate ultimately leads to the formation of UDP-GlcNAc which is the precursor for the formation of sialic acid and oligosaccharide side chains of proteins and lipids.

insulin-mediated glucose uptake can be induced in the absence of sustained hyperglycemia via increased exogenous availability of GlcN/GlcN-6-phosphate and whether this effect is modulated by concomitant chronic hyperglycemia.

\section{Methods}

Animals. Three groups of male Sprague-Dawley rats (Charles River Breeding Laboratories, Inc., Wilmington, MA) were studied: group I, controls $(n=30)$; group II, $90 \%$ partially pancreatectomized rats $(n$ $=10$ ); and group III, $90 \%$ partially pancreatectomized rats treated with phlorizin for 3 wk $(n=10)$. At 4-5 wk of age, all rats $(100-150 \mathrm{~g})$ were anesthetized with pentobarbital $(50 \mathrm{mg} / \mathrm{kg}$ body wt, intraperitoneally), and in groups II and III $90 \%$ of their pancreas was removed according to the technique of Foglia (25), as modified by Bonner-Weir et al. (26). Immediately after surgery rats were housed in individual cages and subjected to a standard light ( 6 a.m. to 6 p.m.)/dark ( 6 p.m. to 6 a.m.) cycle. After surgery rats were weighed twice weekly, and tail vein blood was collected for the determination of nonfasting plasma glucose and insulin concentrations at the same time ( 8 a.m.). Phlorizin $(0.4 \mathrm{~g} / \mathrm{kg}$ body wt, as a $40 \%$ solution in propylene glycol) treatment (group III) was initiated 2-3 wk after surgery and was continued for 3 wk. Phlorizin was administered as a continuous subcutaneous infusion through implantable osmotic minipumps (Alza Corp., Palo Alto, CA). 5 wk after pancreatectomy rats were anesthetized with intraperitoneal injection of pentobarbital $(50 \mathrm{mg} / \mathrm{kg}$ body wt), and indwelling catheters were inserted into the right internal jugular vein and in the left carotid artery, as described previously $(7,27-29)$. The venous catheter was extended to the level of the right atrium, and the arterial catheter was advanced to the level of the aortic arch.

Euglycemic clamp study (Fig. 2). Studies were performed in awake, unstressed, chronically catheterized rats using the euglycemic clamp technique in combination with $\left[3-{ }^{3} \mathrm{H}\right]$ glucose infusion as described previously $(7,27-29)$. Rats were fasted for $6 \mathrm{~h}$ before the in vivo studies. Two experimental designs (PROTOCOL 1 and PROTOCOL 2

\section{PROTOCOL 1}
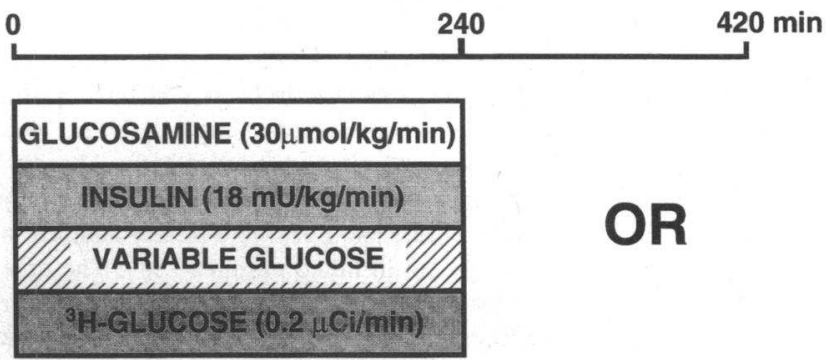

\section{OR}

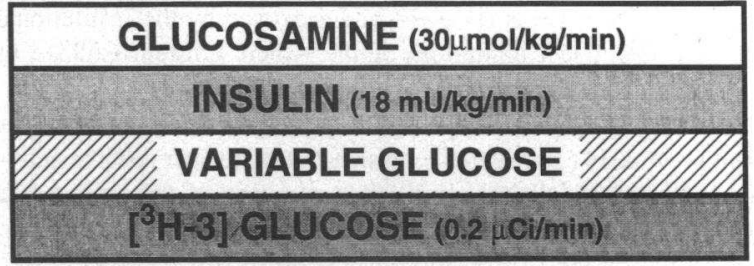

\section{PROTOCOL 2}

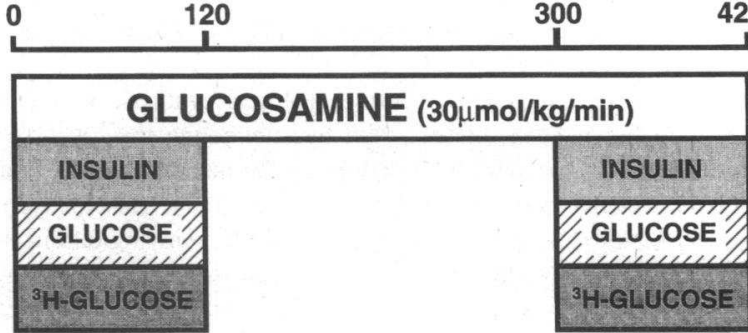

Figure 2. Schematic representation of the two experimental protocols used to examine the effect of increased glucosamine availability on insulin-mediated glucose metabolism. For protocol 1 (top), glucosamine was infused at the rate of $30 \mu \mathrm{mol} / \mathrm{kg} \cdot \min$ during $4-$ or 7 -h euglycemic hyperinsulinemic $(18 \mathrm{mU} / \mathrm{kg} \cdot \mathrm{min})$ clamp studies in combination with $\left[{ }^{3} \mathrm{H}-3\right]$ glucose. For protocol 2 (bottom), glucosamine was infused at the rate of $30 \mu \mathrm{mol} / \mathrm{kg} \cdot \min$ and 7 - and 2-h euglycemic hyperinsulinemic $(18 \mathrm{mU} / \mathrm{kg} \cdot \mathrm{min})$ clamp studies in combination with $\left[{ }^{3} \mathrm{H}-3\right]-$ glucose were performed during the first and last $2 \mathrm{~h}$ of the glucosamine infusion.

in Fig. 2) were used in control rats, while the diabetic groups received protocol 2. Briefly, 5-7 d after the placement of the catheters, primedcontinuous infusions of glucosamine $(30 \mu \mathrm{mol} / \mathrm{kg} \cdot \min )$ or saline and insulin $(108 \mathrm{pmol} / \mathrm{kg} \cdot \mathrm{min})$ were administered for 4 or $7 \mathrm{~h}$ (PROTOCOL 1, Fig. 2), and a variable infusion of a $25 \%$ glucose solution was started at time zero and periodically adjusted to clamp the plasma glucose concentration at the basal level. Studies in protocol 1 were designed to examine the time course of the effects of glucosamine on insulinmediated glucose metabolism in control rats. In an additional group of control rats and in the diabetic and phlorizin-treated diabetic rats, the effect of glucosamine on in vivo insulin action was also assessed with an alternative experimental design. Glucosamine $(30 \mu \mathrm{mol} / \mathrm{kg} \cdot \mathrm{min})$ or saline was infused for $7 \mathrm{~h}$ as above and two euglycemic insulin (108 $\mathrm{pmol} / \mathrm{kg} \cdot \mathrm{min}$ ) clamp studies in combination with $\left[3-{ }^{3} \mathrm{H}\right]$ glucose were performed during the first $2 \mathrm{~h}(\mathrm{t}=0-2 \mathrm{~h})$ and the last $2 \mathrm{~h}(\mathrm{t}=5-7$ h) of the infusion (PROTOCOL 2, Fig. 2). At the beginning of the in vivo study $(t=0)$ a prime-continuous infusion of HPLC-purified [3${ }^{3} \mathrm{H}$ ] glucose (New England Nuclear, Boston, MA; $15-40 \mu \mathrm{Ci}$ bolus, $0.4 \mathrm{mCi} / \mathrm{min}$ ) was initiated and maintained throughout the remainder of the study. Plasma samples for determination of $\left[{ }^{3} \mathrm{H}\right]$ glucose specific activity were obtained at 10 -min intervals throughout the insulin infu- 
sions. Plasma samples for determination of plasma insulin concentrations were obtained at time $-30,0,60,120,240,360$, and $420 \mathrm{~min}$ during the study. The total volume of blood withdrawn was $\sim 5.0 \mathrm{ml} /$ study; to prevent volume depletion and anemia, a solution $(1: 1 \mathrm{vol} /$ $\mathrm{vol}$ ) of $\sim 8.0 \mathrm{ml}$ of fresh blood (obtained by heart puncture from a littermate of the test animal) and heparinized saline $(10 \mathrm{U} / \mathrm{ml})$ was infused. At the end of the in vivo studies, rats were anesthetized (pentobarbital $60 \mathrm{mg} / \mathrm{kg}$ body wt, intravenously), the abdomen was quickly opened, and rectus abdominal muscle and liver were freeze-clamped in situ with aluminum tongs precooled in liquid nitrogen (28). The time from the injection of the anesthetic until freeze-clamping of the liver was $<45 \mathrm{~s}$. All tissue samples were stored at $-80^{\circ} \mathrm{C}$ for subsequent analysis.

The study protocol was reviewed and approved by the Institutional Animal Care and Use Committees of the Albert Einstein College of Medicine.

Whole body glycolysis. The rates of glycolysis were estimated as described previously (28). Briefly, plasma-tritiated water specific activity was determined by liquid scintillation counting of the protein-free supernatant (Somogyi filtrate) before and after evaporation to dryness. Because tritium on the C-3 position of glucose is lost to water during glycolysis, it can be assumed that plasma tritium is present either in tritiated water or $\left[3-{ }^{3} \mathrm{H}\right]$ glucose. Although tritium may also be released during fructose-6-phosphate cycling and/or pentose phosphate cycling, these pathways account for only a small percentage of glucose turnover $(30,31)$.

Glycogen formation in vivo. Muscle glycogen synthesis was estimated by two independent means: first, by subtracting the glycolytic rate from the $R_{\mathrm{d}}$, and second, by determining the increment in skeletal muscle glycogen concentration above fasting levels (28). Muscle glycogen concentration was determined after digestion with amyloglucosidase as described previously (27-29). The intraassay and the interassay coefficients of variation were $<10 \%$ (at $0.250 \mathrm{~g} / 100 \mathrm{~g}$ tissue wt) when a muscle homogenate was assayed as multiple aliquots. Aliquots of the tissue homogenate $(100 \mu \mathrm{l})$ were also used to determine the amount of tritium label in glycogen. Glycogen was precipitated by washing in 10 vol of absolute ethanol and by incubating for $1 \mathrm{~h}$ at $-20^{\circ} \mathrm{C}$. The procedure was repeated three times, and then the precipitate was collected, dried down, and dissolved in water before scintillation counting.

Hexokinases activity. Skeletal muscle hexokinases activity was measured by the continuous assay spectrophotometric method as described by Davidson and Arion (32), with some modifications $(33,34)$. Muscle homogenates $(\sim 200 \mathrm{mg})$ were prepared in $50 \mathrm{mM}$ Hepes, $100 \mathrm{mM}$ $\mathrm{KCl}, 1 \mathrm{mM}$ EDTA, $5 \mathrm{mM} \mathrm{MgCl}$, and $2.5 \mathrm{mM}$ dithioerythritol. Homogenates were centrifuged at $100,000 \mathrm{~g}$ for $45 \mathrm{~min}$. The post-microsomal fraction was assayed at $\mathrm{pH} 7.4$ at $37^{\circ} \mathrm{C}$, in a reaction mixture containing $50 \mathrm{mM}$ Hepes, $100 \mathrm{mM} \mathrm{KCl}, 7.5 \mathrm{mM} \mathrm{MgCl}, 5 \mathrm{mM}$ ATP, $2.5 \mathrm{mM}$ dithioerythritol, $10 \mathrm{mg} / \mathrm{ml}$ albumin, and $0.1,0.2,0.3,0.5$, and $1.0 \mathrm{mM}$ glucose, $0.5 \mathrm{mM} \mathrm{NAD}^{+}, 4 \mathrm{U}$ of glucose-6-phosphate dehydrogenase (Leuconostoc mesenteroides) and the equivalent of $\sim 1 \mathrm{mg}$ of wet liver. The reaction was initiated by the addition of ATP, and the rate of $\mathrm{NAD}^{+}$reduction was recorded at $340 \mathrm{~nm}$. Glucose phosphorylation is determined as the absorbance change in the complete medium minus the absorbance change in the absence of ATP under conditions in which the absorbance is increasing linearly with time (generally from 20 to $40 \mathrm{~min}$ ). To estimate the effect of increased GlcN concentrations on muscle hexokinase, its activity was also assessed as above in the presence of $0,0.25,0.5,1.0,2.0$, and $5.0 \mathrm{mM} \mathrm{GlcN}$ and 0.2 and $2 \mathrm{mM}$ glucose.

Glycogen synthase activity. Muscle glycogen synthase activity was measured by a modification $(27,29)$ of the method of Thomas et al. (35) and is based on the measurement of the incorporation of radioactivity into glycogen from UDP-[U- $\left.{ }^{14} \mathrm{C}\right]$ glucose. Tissue samples $(20-30$ $\mathrm{mg}$ ) were homogenized in $2.0 \mathrm{ml}$ of Tris/ $\mathrm{HCl}$ buffer, $\mathrm{pH} \mathrm{7.8,} \mathrm{containing}$ $10 \mathrm{mM}$ EDTA, $5 \mathrm{mM}$ dithiothreitol, $50 \mathrm{mM} \mathrm{NaF}$, and $2.5 \mathrm{~g} /$ liter rabbit liver glycogen type III. The homogenate was centrifuged at $2,000 \mathrm{~g}$ for $15 \mathrm{~min}\left(\right.$ at $\left.4^{\circ} \mathrm{C}\right)$, and the supernatant was used for glycogen synthase assay by measuring the incorporation of UDP- $\left[\mathrm{U}-{ }^{14} \mathrm{C}\right]$ glucose into gly- cogen at $30^{\circ} \mathrm{C}$. To approximate the in vivo conditions, synthase activity was measured in the presence of physiologic $0.11 \mathrm{mM}$ glucose-6-phosphate. Total glycogen synthase $D$ activity was measured in the presence of $7.2 \mathrm{mM}$ glucose-6-phosphate. For the kinetic analysis, the assay was conducted at final concentrations of $0.003,0.017,0.033,0.09,0.33$, and $1.4 \mathrm{mM}$ uridine diphosphoglucose (UDPG); the data were linearized as Eadie-Hofstee plots and fit using linear regression. The $K_{\mathrm{m}}$ for UDPG is the reciprocal of the slope whereas $V_{\max }$ is the $y$-intercept divided by the slope.

Glycogen phosphorylase. Muscle glycogen phosphorylase activity was measured as described previously (29). This assay is based on the measurement of the incorporation of ${ }^{14} \mathrm{C}$ into glycogen from labeled glucose-1-phosphate. Glycogen phosphorylase $a$, the active phosphorylated enzyme, was assayed in the absence of AMP, and phosphorylase $b$, the total enzyme activity, was assayed in the presence of $5 \mathrm{mM}$ AMP. Tissue homogenates $(20-30 \mathrm{mg})$ were prepared as described above. The supernatant was used for glycogen phosphorylase assay by measuring the incorporation of $\left[{ }^{14} \mathrm{C}\right]$ glucose-1-phosphate into glycogen at $30^{\circ} \mathrm{C}$ in a mixture containing $33 \mathrm{mM}$ Mes, $200 \mathrm{mM} \mathrm{KF}, 0.45 \%$ mercaptoethanol, $15 \mathrm{mM}$ glucose-1-phosphate $(50 \mu \mathrm{Ci} / \mathrm{mmol})$ and $3.4 \mathrm{mg} / \mathrm{ml}$ glycogen. Phosphorylase $b$ was assayed in the same manner except that the mixture contained $100 \mathrm{mM}$ glucose-1-phosphate $(6 \mu \mathrm{Ci} / \mathrm{mmol}), 13.4$ $\mathrm{mg} / \mathrm{ml}$ glycogen, and $5 \mathrm{mM}$ AMP.

Analytical procedures. Plasma glucose was measured by the glucose oxidase method (Glucose Analyzer II; Beckman Instruments, Inc., Palo Alto, CA) and plasma insulin by radioimmunoassay using rat and porcine insulin standards. Plasma $\left[{ }^{3} \mathrm{H}\right]$ glucose radioactivity was measured in duplicate on the supernatants of $\mathrm{Ba}(\mathrm{OH})_{2}$ and $\mathrm{ZnSO}_{4}$ precipitates of plasma samples after evaporation to dryness to eliminate tritiated water. Muscle glucose-6-phosphate concentrations were measured spectrophotometrically as described by Michal (36). Plasma nonesterified fatty acid concentration was determined by an enzymatic method with an automated kit according to the manufacturer's specifications (Waco Pure Chemical Industries, Osaka, Japan). Muscle glycogen was determined as described previously (27-29). Muscle and liver uridinediphosphoglucose (UDP-Glc), uridinediphosphogalactose (UDP-Gal), UDP- $n$-acetylglucosamine (UDP-GlcNAc), and UDP- $n$-acetylgalactosamine (UDP-GalNAc) concentrations were obtained through two sequential chromatographic separations and ultraviolet detection (29, 37, 38). UDP-GlcNAc and UDP-GalNAc coelute with UDP-Glc and UDP-Gal during the solid phase extraction. The retention times for UDP-Glc, UDP-Gal, UDP-GlcNAc, and UDP-GalNAc were 28.5, 30.7, 33.9, and $35.4 \mathrm{~min}$, respectively. Plasma GlcN concentrations were determined by HPLC after quantitative derivatization with phenyl isothiocyanate as described by Anumula and Taylor (39). All HPLC analyses were performed on a HPLC system (Waters Instruments, Inc., Rochester, MN) using a reversed-phase, ion pairing isocratic method, on two C18T (Supelco Inc., Bellefonte, PA) reverse-phase columns $(0.46 \times$ $25 \mathrm{~cm}$ ) in series.

Data for total body glucose uptake and suppression of hepatic glucose production represent the mean values during the last $60 \mathrm{~min}$ of each 120-min time period. Steady state conditions for plasma glucose specific activity were achieved within 40-60 min after insulin in all studies. The hepatic glucose production was calculated as the difference between the tracer-derived rate of appearance and the infusion rate of glucose. Regression analysis of the slopes of ${ }^{3} \mathrm{H}_{2} \mathrm{O} R_{\mathrm{a}}$ (used in the calculation of the rates of glycolysis) was performed at 60 -min intervals throughout the study. All values are presented as the mean \pm SE. Comparisons between groups were made using repeated measures analysis of variance where appropriate. Where $F$ ratios were significant, further comparisons were made using Student $t$ tests.

\section{Results}

\section{General characteristics of the animals}

At the time of the study, the mean body weights were $356 \pm 5$, $332 \pm 11$, and $319 \pm 10 \mathrm{~g}$ for the control, diabetic, and phlorizin- 
Table I. Mean Plasma Glucose, Insulin, and Glucosamine Concentrations during the Euglycemic Clamp Studies Performed as Described in Methods (Protocol 1, Top, and Protocol 2, Bottom)

\begin{tabular}{|c|c|c|c|c|c|c|}
\hline Time (min) & 0 & $60-120$ & $120-180$ & $189-300$ & $300-360$ & $360-420$ \\
\hline Glucose (mM) & $7.1 \pm 0.2$ & $7.0 \pm 0.01$ & $7.0 \pm 0.1$ & $7.2 \pm 0.1$ & $7.2 \pm 0.2$ & $7.1 \pm 0.1$ \\
\hline Insulin (mM) & $0.2 \pm 0.1$ & $2.5 \pm 0.2$ & $2.4 \pm 0.2$ & $2.7 \pm 0.3$ & $2.8 \pm 0.3$ & $2.8 \pm 0.2$ \\
\hline \multirow[t]{2}{*}{$\mathrm{GlcN}(\mathrm{mM})$} & $0.02 \pm 0.01$ & $1.22 \pm 0.04$ & $1.23 \pm 0.04$ & $1.31 \pm 0.04$ & $1.37 \pm 0.05$ & $1.33 \pm 0.07$ \\
\hline & \multicolumn{2}{|c|}{ CON } & \multicolumn{2}{|c|}{ PANX } & \multicolumn{2}{|c|}{ PHLOR } \\
\hline Time (min) & $60-120$ & $360-420$ & $60-120$ & $360-420$ & $60-120$ & $360-420$ \\
\hline Glucose (mM) & $7.1 \pm 0.2$ & $7.2 \pm 0.2$ & $7.0 \pm 0.1$ & $7.0 \pm 0.1$ & $7.1 \pm 0.2$ & $7.1 \pm 0.2$ \\
\hline Insulin (nM) & $2.5 \pm 0.2$ & $2.7 \pm 0.2$ & $2.5 \pm 0.1$ & $2.5 \pm 0.2$ & $2.6 \pm 0.2$ & $2.7 \pm 0.2$ \\
\hline $\mathrm{GlcN}(\mathrm{mM})$ & $1.13 \pm 0.06$ & $1.28 \pm 0.03$ & $1.32 \pm 0.06$ & $1.42 \pm 0.12$ & $1.24 \pm 0.09$ & $1.39 \pm 0.05$ \\
\hline
\end{tabular}

Values are mean \pm SE. CON, control; PANX, diabetic; $P H L O R$, phlorizin-treated diabetic rats.

treated diabetic rats, respectively. The plasma glucose $(19.7 \pm 1.1$ vs. $7.4 \pm 0.2 \mathrm{mM} ; P<0.01)$ concentrations were significantly higher in the diabetic group compared with the control group. Phlorizin treatment restored the plasma glucose concentrations to levels which were not different from control $(7.6 \pm 0.9 \mathrm{mM} ; P=\mathrm{NS})$.

\section{Insulin clamp study (Table I and Figs. 3-5)}

The infusion of glucosamine $(30 \mu \mathrm{mmol} / \mathrm{kg} \cdot \min )$ increased the plasma glucosamine concentrations by $\sim 100$-fold (to $\sim 1.2$ $\mathrm{mM}$ ) in control, diabetic, and phlorizin-treated diabetic rats (Table I). The plasma glucose concentration was maintained at the control basal level during the insulin clamp studies (Table I). Steady state plasma glucose concentrations were similar during the studies within the same group (Table I). The coefficients of variation in plasma glucose and insulin levels were $<5$ and $10 \%$, respectively, in all studies. The plasma FFA concentration was similarly suppressed (by 60-70\%) during the insulin clamp studies with saline and $\mathrm{GlcN}$ infusions.

Protocol 1. Fig. 3 depicts the rates of tissue glucose uptake and the rates of glycolysis and glycogen synthesis during the 7-h euglycemic hyperinsulinemic clamp studies with $\mathrm{GlcN}$ infusion. Prolonged euglycemic hyperinsulinemia with saline (not

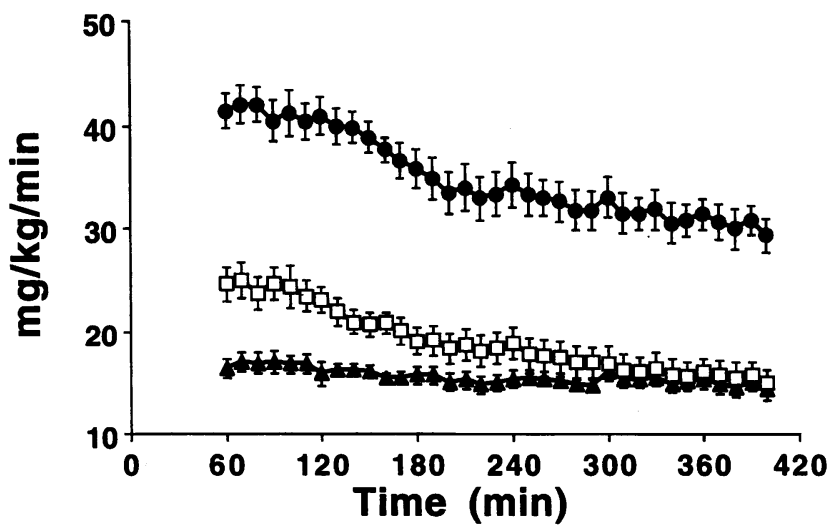

Figure 3. (Protocol 1) The effect of 7-h glucosamine infusions, under hyperinsulinemic conditions, on tissue glucose uptake (solid circles), glycogen synthesis (open squares), and glycolysis (solid triangles) in conscious nondiabetic rats. shown) caused no significant change in the rates of glucose infusion $(5-7 \mathrm{~h}=36.6 \pm 2.7 \mathrm{vs.} 0-2 \mathrm{~h}=39.4 \pm 2.7 \mathrm{mg} / \mathrm{kg} \cdot \mathrm{min}$; $P=\mathrm{NS})$ or in the rates of tissue glucose uptake (360-420 min $=39.1 \pm 3.6$ vs. $60-120 \mathrm{~min}=42.2 \pm 3.7 \mathrm{mg} / \mathrm{kg} \cdot \mathrm{min} ; P$ $=\mathrm{NS})$. The infusion of GlcN caused a progressive decrease in insulin-mediated glucose disposal. During the 4-h insulin clamp studies (not shown) the rate of glucose infusion (5-7 $\mathrm{h}$ $=30.3 \pm 2.0 \mathrm{mg} / \mathrm{kg} \cdot \min$ vs. $0-2 \mathrm{~h}=37.2 \pm 1.6 ; P<0.01)$ and the rate of tissue glucose uptake $(180-240 \mathrm{~min}=34.5 \pm 2.1$ vs. $60-120 \mathrm{~min}=42.5 \pm 1.6 \mathrm{mg} / \mathrm{kg} \cdot \min ; P<0.01)$ decreased by $\sim 19 \%$. During the $7-\mathrm{h}$ insulin clamp studies (Fig. 3 ) the rate of glucose infusion $(5-7 \mathrm{~h}=25.3 \pm 2.0$ vs. $0-2 \mathrm{~h}$ $=37.2 \pm 1.7 \mathrm{mg} / \mathrm{kg} \cdot \min ; P<0.01)$ and the rate of tissue glucose uptake $(360-420 \mathrm{~min}=30.0 \pm 1.5$ vs. $180-240 \mathrm{~min}$ $=34.1 \pm 2.4$ vs. $60-120 \mathrm{~min}=42.1 \pm 1.6 \mathrm{mg} / \mathrm{kg} \cdot \mathrm{min} ; P$ $<0.01$ ) progressively decreased by $\sim 30 \%$. The maximal reduction in $R_{\mathrm{d}}$ during the GlcN infusion was achieved within 5 $h$ in most studies, and the calculated $T_{1 / 2}$ (time required to achieve $50 \%$ of the maximal effect) was $174 \pm 26$ min during the 7-h studies. The decreased tissue glucose uptake during the GlcN infusions was largely due to a marked decrease in the rates of glycogen synthesis (by $28 \%$ at $4 \mathrm{~h}$, and by $39 \%$ at 7 $\mathrm{h}$ ), while the rates of glycolysis were mildly decreased.

Protocol 2. Fig. 4 depicts the rates of tissue glucose uptake and of glucose infusion and Fig. 5 depicts the rates of glycolysis and glycogen synthesis during two euglycemic hyperinsulinemic clamp studies performed during 7-h GlcN infusions in control, diabetic, and phlorizin-treated diabetic rats. Two euglycemic hyperinsulinemic clamp studies were also performed during 7-h saline infusions. Rates of glucose infusion (5-7 h $=34.9 \pm 3.6$ vs. $0-2 \mathrm{~h}=36.6 \pm 3.1 \mathrm{mg} / \mathrm{kg} \cdot \min ; P=\mathrm{NS})$, tissue glucose uptake $(360-420 \mathrm{~min}=37.0 \pm 3.6 \mathrm{vs}$. $60-120$ $\min =39.8 \pm 2.7 \mathrm{mg} / \mathrm{kg} \cdot \mathrm{min} ; P=\mathrm{NS}$ ), glycolysis, and glycogen synthesis did not change significantly during the saline infusion. The infusion of GlcN caused a decrease of $\sim 32 \%$ in insulin-mediated glucose disposal in control and phlorizintreated diabetic rats (Fig. 4). However, GlcN infusion did not cause any further decrease in glucose fluxes in diabetic rats (Fig. 4). In control rats, the decreased tissue glucose uptake during the GlcN infusions was largely due to a marked decrease in the rates of glycogen synthesis (by $41 \%$ ), while the rates of glycolysis were less affected (Fig. 5). In phlorizin-treated diabetic rats, both glycolysis (by $38 \%$ ) and glycogen synthesis 

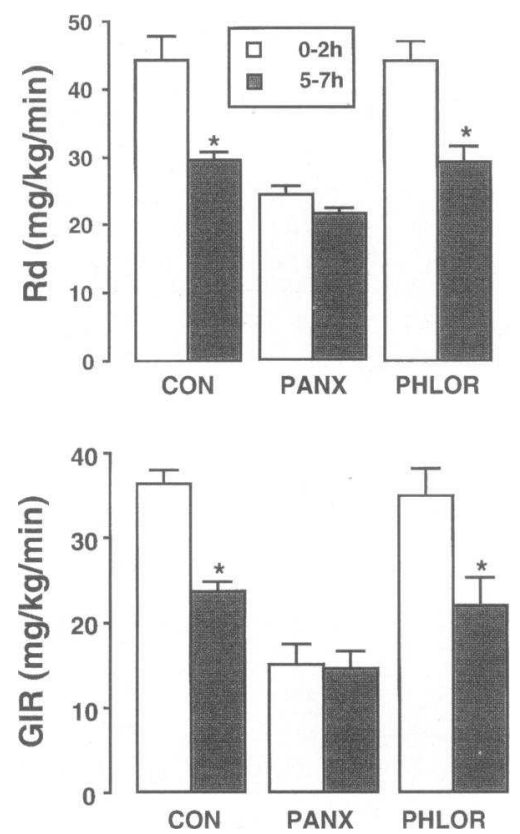

Figure 4. (Protocol 2) Rates of glucose disappearance (top) and of glucose infusion (bottom) in control rats $(C O N), 90 \%$ pancreatectomized diabetic rats $(P A N X)$, and in phlorizin-treated diabetic rats $(P H L O R)$ in the presence of similar concentrations of glucosamine. Results were obtained during identical insulin clamp studies performed during the first and last 2 $h$ of the 7-h glucosamine infusion. $* P<0.015$ $7 \mathrm{~h}$ vs. $0-2 \mathrm{~h}$. (by $27 \%$ ) were significantly decreased by GlcN infusions (Fig. $5)$.

Tissue substrate concentrations (Tables II and III)

Tissue UDP-GlcNAc, UDP-GalNAc, UDP-Glc, and UDP-Gal concentrations (Table II). At the end of the GlcN infusion, skeletal muscle UDP-GlcNAc concentration increased from $\sim 25$ to $\sim 100 \mathrm{nmol} / \mathrm{g}$ wet wt and hepatic UDP-GlcNAc concentration (not shown) increased from $\sim 180$ to $\sim 900 \mathrm{nmol} /$ $\mathrm{g}$ wet wt in all groups. The prolonged GlcN infusion caused similar fold increases in the hepatic UDP-GalNAc concentrations (not shown), while the skeletal muscle UDP-GalNAc concentration was less affected. Interestingly, the GlcN infusion markedly decreased the muscle UDP-Glc concentrations in control and phlorizin-treated diabetic rats, but did not further decrease the muscle UDP-Glc levels in diabetic rats.

Muscle glycogen concentrations (Table III). The fasting muscle glycogen concentration in 6-h fasted rats averaged $7.5 \pm 0.6 \mathrm{mg} / \mathrm{g}$ wet wt. At the end of $7 \mathrm{~h}$ of insulin/GlcN infusion (protocol 1), the muscle glycogen concentrations were increased significantly (Table III, top). The muscle glycogen concentrations at the end of protocol 2 are reported in Table III, bottom. Muscle glycogen was significantly lower in the two diabetic groups compared with the control group and it was significantly lower in the control rats receiving GlcN (Table III) compared with saline $(19.8 \pm 0.7 \mathrm{mg} / \mathrm{g}$ wet $\mathrm{wt})$.

Muscle glucose-6-phosphate concentration (Table III). Skeletal muscle glucose-6-phosphate concentration was significantly and similarly increased during the 7-h insulin clamp studies with saline and GlcN. However, the muscle glucose6-phosphate concentrations were similar in all groups during protocol 2 (Table III).

\section{Muscle enzyme activities (Table III and Fig. 6)}

Kinetic analysis of muscle glycogen synthase (Table III). Insulin exerts most of its short-term effects on skeletal muscle glycogen synthase by decreasing the enzyme's phosphorylation which in turn leads to increased affinity for its substrate, i.e.,
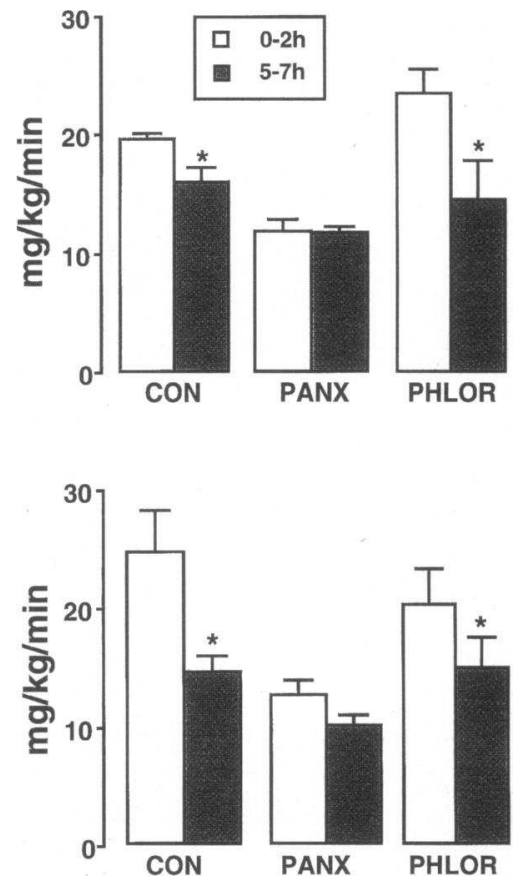

Figure 5. (Protocol 2) Rates of glycolysis (top) and of glycogen synthesis (bottom) in control rats $(C O N), 90 \%$ pancreatectomized diabetic rats $(P A N X)$, and in phlorizin-treated diabetic rats $(P H L O R)$ in the presence of similar concentrations of glucosamine. Results were obtained during identical insulin clamp studies performed during the first and last $2 \mathrm{~h}$ of the 7$\mathrm{h}$ glucosamine infusion. $* P<0.015-7 \mathrm{~h}$ vs. 0$2 \mathrm{~h}$.

decreased $K_{\mathrm{m}}$ for UDP-Glc. In all experimental groups, insulin caused a significant activation of the enzyme with decreased $K_{\mathrm{m}}$. However, significantly higher $K_{\mathrm{m}}$ was demonstrated in both diabetic groups compared with controls (Table III). Insulin with GlcN and saline infusions (Table III) caused a similar activation of muscle glycogen synthase in control rats. Muscle glycogen phosphorylase a activities (not shown) were similar in all groups.

Kinetic analysis of muscle hexokinase activity (Table III and Fig. 6). The kinetics of the skeletal muscle hexokinase was not affected by the prolonged GlcN infusions in all groups compared with saline (Table III). However, the addition of increasing concentrations of GlcN in vitro caused a dose-dependent inhibition in muscle hexokinases activities with an $\mathrm{EC}_{50}$ of $\sim 0.9 \mathrm{mM}$ (Fig. 6). To investigate whether GlcN acted as a competitive inhibitor of hexokinase, we also examined the effect of increasing GlcN concentrations on muscle hexokinase activity at saturating glucose concentrations $(2.0 \mathrm{mM})$. The $\mathrm{GlcN}$-induced inhibition of hexokinase activity was blunted under the latter experimental conditions suggesting that its effect on hexokinase activity is largely due to substrate competition between Glc and GlcN.

\section{Discussion}

The present studies demonstrate that increased glucosamine availability in vivo impairs insulin's ability to stimulate glucose uptake and glycogen synthesis in normoglycemic but not in chronically hyperglycemic conscious rats. Though the prolonged exposure of insulin-sensitive tissues to high glucose and/ or insulin concentrations induced the impairment of insulinmediated glucose uptake in vitro (14-20) and in vivo (7-11), the biochemical mechanism( $s$ ) of this phenomenon has not been delineated. Marshall et al. (14-17), in a series of elegant studies in primary culture of adipose cells, provided strong experimental evidence for the key role of the "glucosamine biosyn- 
Table II. Skeletal Muscle UDP-Glc, UDP-Gal, UDP-GlcNAc, and UDP-GalNAc Concentrations at the End (GlcN) of Euglycemic Clamp Studies Performed in the Presence of Glucosamine Infusion (30 $\mu \mathrm{mol} / \mathrm{kg} \cdot \mathrm{min})$ in 6-h Fasted Conscious Control (CON), Diabetic (PANX), and Phlorizin-treated Diabetic (PHLOR) Rats

\begin{tabular}{|c|c|c|c|c|c|c|}
\hline \multirow[b]{2}{*}{ Groups } & \multicolumn{2}{|c|}{ CON } & \multicolumn{2}{|c|}{ PANX } & \multicolumn{2}{|c|}{ PHLOR } \\
\hline & Basal & GlcN & Basal & GlcN & Basal & GlcN \\
\hline UDP-Glc (nmol/g) & $23.9 \pm 2.2$ & $9.6 \pm 2.4^{*}$ & $8.7 \pm 0.6^{\ddagger}$ & $6.7 \pm 0.9$ & $16.8 \pm 1.5$ & $5.2 \pm 0.9 *$ \\
\hline UDP-Gal (nmol/g) & $6.7 \pm 0.9$ & $3.2 \pm 0.6^{*}$ & $4.6 \pm 0.6^{\ddagger}$ & $2.5 \pm 0.5^{*}$ & $6.4 \pm 1.4$ & $1.9 \pm 0.4^{*}$ \\
\hline UDP-GlcNAc (nmol/g) & $20.4 \pm 1.7$ & $96.0 \pm 8.4^{*}$ & $27.1 \pm 2.0$ & $99.6 \pm 7.2^{*}$ & $25.6 \pm 0.5$ & $89.5 \pm 5.6 *$ \\
\hline UDP-GalNAc (nmol/g) & $6.8 \pm 0.2$ & $15.0 \pm 2.6^{*}$ & $6.5 \pm 0.3$ & $12.3 \pm 1.2^{*}$ & $7.6 \pm 1.3$ & $9.2 \pm 1.5$ \\
\hline
\end{tabular}

Basal values are obtained from additional control, diabetic, and phlorizin-treated diabetic rats infused with saline. ${ }^{*} P<0.01 \mathrm{GlcN}$ vs. basal; ${ }^{\ddagger} P$ $<0.01$ vs. CON basal. Values are mean \pm SE.

thetic pathway" for the desensitization of the glucose transport system induced by prolonged incubations with glucose, insulin, and glutamine. The present studies were designed to test the above hypothesis in the intact animal with particular emphasis on the pathways of glucose disposal in a major insulin target tissue, e.g., skeletal muscle. During insulin clamp studies, whole body glucose uptake and skeletal muscle glycogen synthesis were markedly and progressively decreased in the presence of increased glucosamine availability. Glucosamine-induced peripheral insulin resistance was demonstrated with two different experimental protocols in control rats and appears to require $\sim 3-5 \mathrm{~h}$ to be fully expressed $\left(\mathrm{T}_{1 / 2}=174 \pm 26 \mathrm{~min}\right)$. Importantly, increased glucosamine availability did not cause a further impairment in insulin-mediated glucose uptake in diabetic rats maintained hyperglycemic for $\sim 3 \mathrm{wk}$. Normalization of the plasma glucose concentration in diabetic rats, by phlorizin treatment, restored the potent effects of increased glucosamine availability on insulin-mediated glucose uptake. These observations

Table III. Skeletal Muscle Glycogen and Glucose-6-Phosphate (Glc-6-P) Concentrations and $V_{\max }$ and $K_{m}$ of the Glc-6-Pindependent Form of the Glycogen Synthase (GS) and $V_{\max }$ and $K_{m}$ of Hexokinase (HK) at the End of Euglycemic Clamp Studies Performed as Described in Methods (Protocol 1, Top, and Protocol 2, Bottom)

\begin{tabular}{|c|c|c|c|}
\hline Groups & \multicolumn{2}{|c|}{ Saline } & GlcN \\
\hline Glycogen, $(\mathrm{mg} / \mathrm{g})$ & \multicolumn{2}{|c|}{$25.2 \pm 0.8$} & $21.0 \pm 0.9 *$ \\
\hline Glc-6-P (nmol/g) & \multicolumn{2}{|c|}{$472 \pm 51$} & $523 \pm 64$ \\
\hline GS $V_{\max }(\mu \mathrm{mol} / \mathrm{g} / \mathrm{min})$ & \multicolumn{2}{|c|}{$0.63 \pm 0.05$} & $0.62 \pm 0.07$ \\
\hline $\mathrm{GS} K_{\mathrm{m}}(\mathrm{mM})$ & \multicolumn{2}{|c|}{$0.21 \pm 0.04$} & $0.23 \pm 0.05$ \\
\hline $\mathrm{HK} V_{\max }(\mu \mathrm{mol} / \mathrm{g} / \mathrm{min})$ & \multicolumn{2}{|c|}{$2.3 \pm 0.6$} & $2.4 \pm 0.3$ \\
\hline $\mathrm{HK} K_{\mathrm{m}}(\mathrm{mM})$ & \multicolumn{2}{|c|}{$0.17 \pm 0.03$} & $0.21 \pm 0.08$ \\
\hline Groups & CON & PANX & PHLOR \\
\hline Glycogen $(\mathrm{mg} / \mathrm{g})$ & $16.6 \pm 0.6$ & $13.9 \pm 1.2 *$ & $14.1 \pm 1.0^{*}$ \\
\hline Glc-6-P (nmol/g) & $254 \pm 38$ & $251 \pm 36$ & $231 \pm 58$ \\
\hline $\mathrm{GS} V_{\max }(\mu \mathrm{mol} / \mathrm{g} / \mathrm{min})$ & $0.69 \pm 0.08$ & $0.42 \pm 0.09 *$ & $0.46 \pm 0.11^{*}$ \\
\hline GS $K_{\mathrm{m}}(\mathrm{mM})$ & $0.14 \pm 0.02$ & $0.21 \pm 0.02 *$ & $0.19 \pm 0.03 *$ \\
\hline HK $V_{\max }(\mu \mathrm{mol} / \mathrm{g} / \mathrm{min})$ & $2.1 \pm 0.3$ & $1.6 \pm 0.5$ & $2.0 \pm 0.6$ \\
\hline HK $K_{\mathrm{m}}(\mathrm{mM})$ & $0.18 \pm 0.06$ & $0.27 \pm 0.08$ & $0.20 \pm 0.06$ \\
\hline
\end{tabular}

Values are mean \pm SE. $* P<0.05$ vs. Saline or CON. indicate that increased flux through the glucosamine pathway can generate marked insulin resistance in skeletal muscle in vivo and that this effect is not additive to the insulin resistance induced by chronic hyperglycemia.

Several studies have attempted to define the mechanism(s) by which prolonged glucose and insulin infusions lead to decreased insulin-mediated glucose uptake in skeletal muscle. Hager et al. (40) in 72-h glucose-infused rats and Hansen et al. (41) in 7-h glucose-infused hindquarters showed downregulation of insulin-stimulated glucose uptake, in the absence of any alteration in insulin binding or insulin receptor tyrosine kinase activity. Similarly, Vuorinen-Markkola et al. (42) showed marked decreases in insulin action on skeletal muscle glucose uptake and glycogen storage in insulin-dependent diabetes mellitus patients infused with glucose for $24 \mathrm{~h}$. Using a different experimental approach, i.e., the reversal of glucoseinduced insulin resistance in phlorizin-treated diabetic rats, we reached a similar conclusion $(7,10,27)$. In fact, $90 \%$ partial pancreatectomy resulted in defects in both skeletal muscle glucose transport/phosphorylation and in glycogen synthase activ-

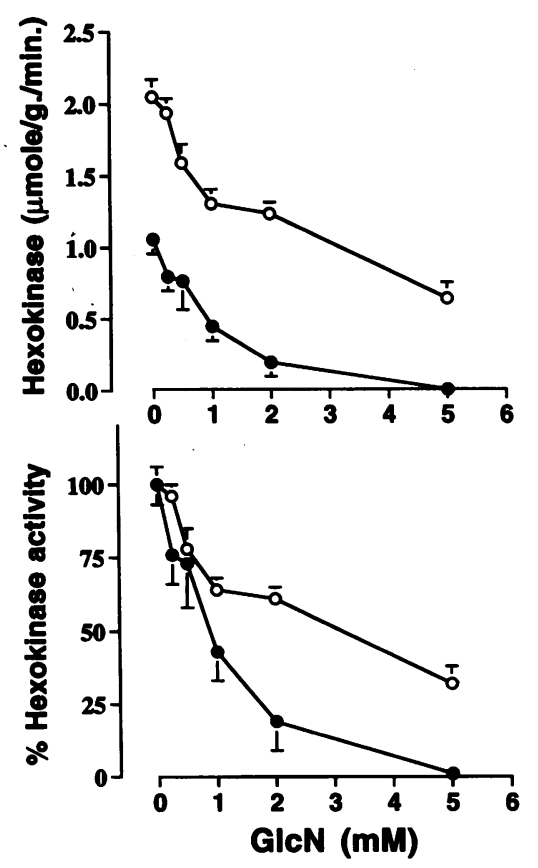

Figure 6. Effect of increasing in vitro glucosamine concentrations on muscle hexokinase activity in the presence of 0.2 $\mathrm{mM}$ (solid circles) and 2 mM (open circles) glucose. Results are expressed as activity (top) and as a percentage of the activity at zero $\mathrm{GlcN}$ (bottom). 
ity $(27,28)$. However, the normalization of the plasma glucose concentration by phlorizin restored insulin-stimulated glucose uptake $(7,27)$ and $3-O$-methylglucose transport $(10)$ to normal levels without improving the impaired skeletal muscle glycogen synthase activity (27). This effect on glucose transport activity was not due to increased gene expression of GLUT 4 or GLUT 1 (10). Sivitz et al. (12) also reported no change in GLUT4 mRNA in adipose cells from streptozotocin/diabetic rats after near-normalization of the plasma glucose concentration by phlorizin treatment and concluded that the relative glycemic state does not influence GLUT4 mRNA expression in vivo. Importantly, a recent study by Dimitrakoudis et al. (13) indicated that, in phlorizin-treated streptozotocin/diabetic rats, GLUT4 protein level in skeletal muscle tends to return toward normal levels in the plasma membrane fraction but not in the intracellular pool, suggesting that improved translocation of GLUT4 is a potential mechanism for the increased skeletal muscle glucose uptake after correction of hyperglycemia by phlorizin treatment. Thus, defective insulin stimulation of the glucose transport system appears to be the major cellular manifestation of prolonged hyperglycemia in insulin-sensitive tissues and defects in either or both glucose transporters' translocation and/or "intrinsic activity" may be involved. A recent report by Robinson et al. (21) demonstrated that preincubation of isolated skeletal muscle in the presence of high glucosamine $(10-22 \mathrm{mM})$ induced a marked decrease in basal and insulin-stimulated glucose transport. Interestingly, this study showed no effects of the high glucosamine concentrations on insulin receptor number and tyrosine kinase activity and on GLUT4 gene expression (21). Thus, at least in an isolated muscle preparation, glucosamine was able to induce insulin resistance with similar features with that induced by prolonged exposure to high glucose (10-13, 40-42). However, it may be argued that the glucosamine concentrations which caused a significant decrease in insulin-mediated glucose transport activity in the study by Robinson et al. (21) were much higher than those required to reproduce the increased formation of glucosamine-6-phosphate in the presence of high glucose.

In fact, the "glucosamine hypothesis," as proposed by Marshall and colleagues (14-17), is based on the observation that $\sim 1-3 \%$ of the glucose metabolized in insulin-sensitive tissues is through the glucosamine biosynthetic pathway (Fig. 1). Since the glucose concentrations required to induce insulin resistance in short-term studies is $\sim 20 \mathrm{mM}$ and since the affinity of glucosamine for the glucose transport system is approximately fourfold lower than that of glucose, it may be calculated that extracellular glucosamine concentrations of $0.8-2.4 \mathrm{mM}$ may be required to simulate the glucose flux through the glucosamine pathway under conditions which cause maximal desensitization of the glucose transport system to insulin stimulation. Similarly, the initial glucose flux during glucose "desensitization protocols" (high glucose plus high insulin) is $\sim 420 \mu \mathrm{mol} / \mathrm{kg} \cdot \mathrm{min}$ of which $8 \mu \mathrm{mol} / \mathrm{kg} \cdot \min (\sim 2 \%)$ may enter the glucosamine pathway. Taking into account the lower affinity of glucosamine versus glucose for the glucose transport system, it may be calculated that the infusion of glucosamine at a rate of $\sim 32 \mu \mathrm{mmol} /$ $\mathrm{kg} \cdot \min$ may be required to reproduce the flux of glucose to glucosamine-6-phosphate during glucose-induced insulin resistance. Based on these estimates, we selected to increase the plasma glucosamine concentrations to $\sim 1.2 \mathrm{mM}$ by infusing glucosamine at a rate of $30 \mu \mathrm{mol} / \mathrm{kg} \cdot \min$ (Table I). These circulating levels of glucosamine closely approximate the con- centration of GlcN ( $1 \mathrm{mM}$ for $5 \mathrm{~h}$ ) required for maximal desensitization of the glucose transport system in isolated adipose cells (14) but are lower than the GlcN concentration ( $10 \mathrm{mM}$ for 60-180 $\mathrm{min}$ ) which induced decreased insulin-mediated glucose transport in isolated muscle (21). Thus, in protocol 1 , glucosamine availability was increased to $\sim 1.2 \mathrm{mM}$ during $4-\mathrm{h}$ and 7-h euglycemic ( $7 \mathrm{mM}$ ) hyperinsulinemic ( $2.5 \mathrm{nM})$ clamp studies. The infusion of glucosamine was associated with a time-dependent decline in the rates of glucose uptake and glycogen synthesis during the insulin clamp studies. We first demonstrated a 19\% decrease in insulin-mediated glucose uptake after 4-h GlcN infusions during insulin clamp studies. This decrease was accounted for by a $30 \%(\sim 7.5 \mathrm{mg} / \mathrm{kg} \cdot \mathrm{min})$ decrease in glycogen synthesis and an $11 \%(\sim 2.0 \mathrm{mg} / \mathrm{kg} \cdot \mathrm{min})$ decrease in glycolysis. However, since the effect of GlcN on $R_{\mathrm{d}}$ did not reach a plateau by the end of these studies, we also performed 7-h GlcN infusions in combination with insulin clamp studies. The GlcN-induced decrease in $R_{\mathrm{d}}$ reached a maximal effect by $5 \mathrm{~h}$ with a decrease of $\sim 30 \%$ compared with the first $2 \mathrm{~h}$ of infusion in the same rats or with saline control studies. This experimental design also allowed us to evaluate the time course of the effect of glucosamine on glucose uptake. At the plasma glucosamine concentrations achieved in our study, the time required for half maximal effect of the amino sugar on $R_{\mathrm{d}}$ was $\sim 3 \mathrm{~h}$ (Fig. 3). However, results by Robinson et al. (21) in isolated muscle suggest that a shorter exposure time may be sufficient at higher GlcN concentrations. During protocol 1, the effect of prolonged $\mathrm{GlcN} /$ insulin infusions on $R_{\mathrm{d}}$ was largely due to a decreased rate of glycogen synthesis. Particularly, the further decrease in glucose disposal between 4 and $7 \mathrm{~h}$ was entirely due to decreased glycogen synthesis while the rate of glycolysis did not change significantly. Furthermore, decreased skeletal muscle glycogen synthase activity and increased glucose-6-phosphate concentrations were associated with the 7-h clamp studies independently of the presence of increased GlcN availability. These observations suggested that the above experimental design may also induce some time-dependent impairment in muscle glycogen synthesis due to prolonged insulinization and this may complicate the interpretation of the GlcNspecific effects on glucose disposal.

Thus, we also examined the effect of glucosamine infusions on insulin-mediated glucose uptake and metabolism with an alternative experimental approach (PROTOCOL 2 in Fig. 2). The infusion of glucosamine was again associated with a decrease of $\sim 32 \%$ in $R_{\mathrm{d}}$, despite no impairment of muscle glycogen synthase kinetics or increase in glucose-6-phosphate concentrations. Both glycogen synthesis and glycolysis were significantly impaired during the second clamp study compared with the first or with saline control studies. However, though glycolysis was significantly decreased by $22 \%$ during protocol 2 , the decline in glycogen synthesis was more severe and accounted for $\sim 80 \%$ of the decreased $R_{\mathrm{d}}$. The proportionally greater decrease in glycogen synthesis suggests that a step beyond glucose transport/phosphorylation was also involved in the GlcN-induced insulin resistance. Since muscle glycogen synthase was normally activated by insulin, it is likely that the marked decrease in muscle UDP-Glc concentrations contributed to the impairment of glycogen synthesis. Thus, increased GlcN availability can induce peripheral insulin resistance in vivo in conscious nondiabetic rats in the absence of prolonged exposure to high glucose and insulin.

Can the increased routing of glucose in the glucosamine 
pathway cause further desensitization of glucose uptake in diabetic rats? We reasoned that if the impaired insulin action on skeletal muscle glucose uptake in diabetic rats is due to a chronic increase in the flux of glucose carbons through the glucosamine pathway, the short-term effects of glucosamine infusion on insulin-mediated glucose uptake may be blunted in chronically hyperglycemic diabetic rats versus nondiabetic rats. Similarly, we hypothesized that the ability of glucosamine infusions to generate peripheral insulin resistance may be restored in diabetic rats by normalizing the plasma glucose concentration with phlorizin. Thus, we examined the short-term regulation of glucose uptake and intracellular glucose disposal by the enhanced carbon flux through the glucosamine pathway in chronically hyperglycemic diabetic rats and in phlorizin-treated diabetic rats. Glucosamine infusions generated similar plasma GlcN and muscle UDP-GlcNAc concentrations in all groups. However, peripheral glucose uptake, glycolysis, and glycogen synthesis were not significantly affected by increased GlcN availability in diabetic rats. Long-term normalization of the plasma glucose concentrations by phlorizin treatment restored insulin-mediated glucose uptake, but not glycogen synthesis, to normal in diabetic rats. Correction of hyperglycemia also restored the marked effects of the GlcN infusion on insulin-mediated glucose uptake, glycolysis, and glycogen synthesis. These alterations in glucose fluxes occurred in the absence of significant changes in the kinetics of muscle glycogen synthase and hexokinase and in the concentration of glucose-6-phosphate. However, the sustained increase in GlcN availability caused a marked decrease in skeletal muscle UDP-Glc concentrations in control and phlorizin-treated diabetic rats. This may certainly contribute to the marked reduction in the in vivo rates of glycogen deposition during the GlcN infusions. In diabetic rats, the basal concentrations of UDP-Glc were significantly lower than in the other two groups and were only marginally decreased by GlcN. It has been suggested that the depletion of the UDP-Glc and UDP-Gal pools induced by high GlcN may mediate some of its effects on glucose uptake (21). The present observation of similar effects of GlcN on UDP-GlcNAc concentrations, but not UDP-Glc concentrations, in diabetic rats appears to support the association between decreased muscle glucose uptake and depletion of UDP-Glc.

The observation that in protocol 2 a sustained increase in the availability of GlcN caused a marked impairment in glucose uptake, glycogen synthesis, and glycolysis in the absence of significant elevations in the muscle glucose-6-phosphate concentrations suggests that GlcN acts at an early step of glucose uptake. Though most previous studies point toward an impairment in glucose transport system as the major mechanism of action, an alteration in the phosphorylation of glucose cannot be excluded. Glucosamine has been shown to limit glucose phosphorylation in pancreatic beta cells, presumably via reversible inhibition of glucokinase (43). Much less is known on the effects of increased GlcN on the activity of muscle hexokinases. Though the $V_{\max }$ and $K_{\mathrm{m}}$ of muscle hexokinase were not affected at the end of the prolonged GlcN infusions, the data reported in Fig. 6 demonstrate an inhibitory effect of increasing GlcN concentrations on the muscle glucose-phosphorylating capacity. Thus, GlcN acts as a reversible antagonist of hexokinases probably competing with glucose for the active site, since its effect was largely overcome by increasing the glucose concentration. The relevance of this in vitro finding to the interpretation of the clamp studies is difficult to evaluate since the absolute concen- trations of glucose and GlcN available for muscle hexokinases are not known. However, the relative concentrations of the two substrates in the extracellular space (ratio of glucose/GlcN $=\sim 5.5$ ) are likely to raise in the intracellular space due to the lower affinity of the glucose transporters for GlcN versus glucose and, in the presence of such an excess of glucose over GlcN, the modest inhibition of glucose phosphorylation may not translate into a significant reduction in glucose uptake. Finally, it should be pointed out that though we have demonstrated a marked decrease in the ability of supraphysiologic insulin concentrations to stimulate peripheral glucose uptake in the presence of a sustained increase in glucosamine availability, further studies will be needed to verify whether a similar effect is also present at low physiologic insulin concentrations.

In summary, increased glucosamine availability induces peripheral insulin resistance in conscious nondiabetic rats. The observation that the ability of prolonged glucosamine infusions to induce peripheral insulin resistance is lost in diabetic rats and is restored in phlorizin-treated diabetic rats suggests that the deleterious effects of chronic hyperglycemia and glucosamine infusions on peripheral insulin resistance are not additive and may act on a common pathway.

\section{Acknowledgments}

The authors thank Gary Sebel, Meizhu Hu, and Rong Liu for their excellent technical assistance, and Dr. Norman Fleischer and Dr. Harry Shamoon for their critical reading of the manuscript.

This work was supported by grants from the National Institutes of Health (R029-DK 45024 and R01-DK 48321) and the Juvenile Diabetes Foundation and by the Core Laboratories of the Albert Einstein Diabetes Research and Training Center (DK 20541). Dr. Rossetti is the recipient of a Career Scientist Award from the Irma T. Hirschl Trust. Dr. Hawkins and Dr. Barzilai were the recipients of postdoctoral research fellowships from the Juvenile Diabetes Foundation.

\section{References}

1. DeFronzo, R. A., D. Diebert, R. Hendler, and P. Felig. 1979. Insulin sensitivity and insulin binding in maturity onset diabetes. J. Clin. Invest. 63:939946.

2. Kolterman, O. G., R. S. Gray, J. Griffin, P. Burstein, J. Insel, J. A. Scarlett, and J. M. Olefsky. 1981. Receptor and postreceptor defects contribute to the insulin resistance in non-insulin-dependent diabetes mellitus. J. Clin. Invest. 68:957-959.

3. Rizza, R. A., L. J. Mandarino, and J. E. Gerich. 1981. Mechanism and significance of insulin resistance in noninsulin-dependent diabetes mellitus. Diabetes. 30:990-995.

4. DeFronzo, R. A., R. Hendler, and D. Simonson. 1982. Insulin resistance is a prominent feature of insulin dependent diabetes. Diabetes. 31:795-801.

5. Yki-Jarvinen, H., and V. A. Koivisto. 1986. Natural history of insulin resistance in type I diabetes. $N$. Engl. J. Med. 315:224-230.

6. Unger, R. H., and S. Grundy. 1985. Hyperglycaemia as an inducer as well as a consequence of impaired islet cell function and insulin resistance: implications for the management of diabetes. Diabetologia. 28:119-121.

7. Rossetti, L., D. Smith, G. I. Shulman, D. Papachristou, and R. A. DeFronzo 1987. Correction of hyperglycemia with phlorizin normalizes tissue sensitivity to insulin in diabetic rats. J. Clin. Invest. 79:1510-1515.

8. Yki-Jarvinen, H., E. Helve, and V. A. Koivisto. 1987. Hyperglycemia decreases glucose uptake in type 1 diabetes. Diabetes. 36:892-896.

9. Richter, E. A., B. F. Hansen, and S. A. Hansen. 1988. Glucose-induced insulin resistance of skeletal muscle glucose transport and uptake. Biochem. J. 252:733-737.

10. Kahn, B. B., G. I. Shulman, R. A. DeFronzo, S. W. Cushman, and L. Rossetti. 1991. Normalization of blood glucose in diabetic rats with phlorizin treatment reverses insulin resistant glucose transport in adipose cells without restoring glucose transporter gene expression. J. Clin. Invest. 87:561-570.

11. Kahn, B. B., L. Rossetti, H. F. Lodish, and M. J. Charron. 1991. Decreased in vivo glucose uptake but normal expression of GLUT1 and GLUT4 in skeletal muscle. J. Clin. Invest. 87:2197-2206. 
12. Sivitz, W. I., S. L. DeSautel, T. Kayano, G. I. Bell, and J. E. Pessin. 1990. Regulation of glucose transporter messenger RNA levels in rat adipose tissue by insulin. Mol. Endocrinol. 4:583-588.

13. Dimitrakoudis, D., T. Ramlal, S. Rastogi, M. Vranic, and A. Klip. 1992. Glycemia regulates the glucose transporter number in the plasma membrane of the rat skeletal muscle. Biochem. J. 284:341-348.

14. Marshall, S., V. Bacote, and R. R. Traxinger. 1992. Discovery of a metabolic pathway mediating desensitization of the glucose transport system: role of hexosamine biosynthesis in the induction of insulin resistance. J. Biol. Chem. 266:4706-4712.

15. Marshall, S., V. Bacote, and R. R. Traxinger. 1991. Complete inhibition of glucose-induced desensitization of the glucose transport system by inhibitors of mRNA synthesis. J. Biol. Chem. 266:10155-10161.

16. Marshall, S., W. T. Garvey, and R. R. Traxinger. 1991. New insights into the metabolic regulation of insulin action and insulin resistance: role of glucose and amino acids. FASEB (Fed. Am. Soc. Exp. Biol.) J. 5:3031-3036.

17. Traxinger, R. R., and S. Marshall. 1991. Coordinate regulation of glutamine:fructose-6-P amidotransferase activity by insulin, glucose and glutamine. $J$. Biol. Chem. 266:10148-10154.

18. Garvey, W. T., J. M. Olefsky, and S. Marshall. 1985. Insulin receptor downregulation is linked to an insulin-induced postreceptor defect in the glucose transport system in rat adipocytes. J. Clin. Invest. 76:22-30.

19. Garvey, W. T., J. M. Olefsky, S. Matthaei, and S. Marshall. 1987. Glucose and insulin co-regulate the glucose transport system in primary cultured adipocytes. A new mechanism of insulin resistance. J. Biol. Chem. 262:189-197.

20. Traxinger, R. R., and S. Marshall. 1989. Role of aminoacids in modulating glucose-induced desensitization of the glucose transport system. J. Biol. Chem. 264:20910-20916.

21. Robinson, K. A., D. A. Sens, and M. G. Buse. 1993. Pre-exposure to glucosamine induces insulin resistance of glucose transport and glycogen synthesis in isolated rat skeletal muscles. Diabetes. 42:1333-1346.

22. Traxinger, R. R., and S. Marshall. 1992. Insulin regulation of pyruvate kinase activity in isolated adipocytes. Crucial role of glucose and the hexosamine biosynthesis pathway in the expression of insulin action. J. Biol. Chem. 267:97189723.

23. Crook, E. D., M. C. Daniels, T. M. Smith, and D. A. McClain. 1993. Regulation of insulin-stimulated glycogen synthase activity by overexpression of glutamine:fructose-6-phosphate amidotransferase in rat-1 fibroblasts. Diabetes. 42:1289-1296

24. Daniels, M. C., P. Kansal, T. M. Smith, A. J. Paterson, J. E. Kudlow, and D. A. McClain. 1993. Glucose regulation of transforming growth factor- expression is mediated by products of the hexosamine biosynthesis pathway. Mol. Endocrinol. 7:1041-1048.

25. Foglia, V. G. 1944. Caracteristicas de la diabetes en la rata. Rev. Soc. Argent. Biol. 20:21-37.

26. Bonner-Weir, S., D. F. Trent, and G. C. Weir 1983. Partial pancreatectomy in the rat and subsequent defect in glucose-induced insulin release. J. Clin. Invest. 71:1544-1553.

27. Rossetti, L., and M. R. Laughlin. 1989. Correction of chronic hyperglyce- mia with vanadate, but not phlorizin, normalizes in vivo glycogen repletion and in vitro glycogen synthase activity in diabetic skeletal muscle. J. Clin. Invest. 84:892-899.

28. Rossetti, L., and A. Giaccari. 1990. Relative contribution of glycogen synthesis and glycolysis to insulin-mediated glucose uptake. A dose-response euglycemic clamp study in normal and diabetic rats. J. Clin. Invest. 85:17851792.

29. Rossetti, L., and M. Hu. 1993. Skeletal muscle glycogenolysis is more sensitive to insulin than is glucose transport/phosphorylation. Relation to the insulin-induced inhibition of hepatic glucose production. J. Clin. Invest. 92:29632974.

30. Karlander, S., A. Roovete, M. Vranic, and S. Efendic. 1986. Glucose and fructose -6-phosphate cycle in humans. Am. J. Physiol. 251:E530-E536.

31. Hostler, K. Y., and B. R. Landau. 1967. Estimation of the pentose cycle contribution to glucose metabolism in tissue in vivo. Biochemistry. 6:2961-2964.

32. Davidson, A. L., and W. J. Arion. 1987. Factors underlying significant underestimations of glucokinase activity in crude liver extracts: physiological implications of higher cellular activity. Arch. Biochem. Biophys. 253:156-167.

33. Rossetti, L., A. Giaccari, N. Barzilai, K. Howard, G. Sebel, and M. Hu. 1993 Mechanism by which hyperglycemia inhibits hepatic glucose production in conscious rats. Implications for the pathophysiology of fasting hyperglycemia. $J$. Clin. Invest. 92:1126-1134.

34. Barzilai, N., and L. Rossetti. 1993. Role of glucokinase and glucose-6phosphatase in the acute and chronic regulation of hepatic glucose fluxes by insulin. J. Biol. Chem. 268:25019-25025.

35. Thomas, J. A., K. K. Schlender, and J. Larner. 1968. A rapid filter paper assay for UDPG-glycogen glucosyltransferase, including an improved biosynthesis of UDP- $\left[{ }^{14} \mathrm{C}\right]$ glucose. Anal. Biochem. 25:486-499.

36. Michal, G. 1985. D-Glucose-6-Phosphate. In Methods of Enzymatic Analysis. Vol. VI. N. U. Bergmeyer, editor. VCH Publishers, Weinheim. 191-198.

37. Giaccari, A., and L. Rossetti. 1989. Isocratic high-performance liquid chromatographic determination of the concentration and specific radioactivity of phosphoenolpyruvate and uridine diphosphate glucose in tissue extracts. $J$. Chromatogr. 497:69-78.

38. Giaccari, A., and L. Rossetti. 1992. Predominant role of gluconeogenesis in the hepatic glycogen repletion of diabetic rats. J. Clin. Invest. 89:36-45.

39. Anumula K. R and P. B. Taylor. 1991. Quantitative determination of phenyl isothiocyanate-derivatized amino sugars and amino sugar alcohols by highperformance liquid chromatography. Anal. Biochem. 197:113-120.

40. Hager, S. R., A. L. Jochen, and R. K. Kalkhoff. 1991. Insulin resistance in normal rats infused with glucose for 72h. Am. J. Physiol. 260:E353-E362.

41. Hansen, B. F., S. A. Hansen, T. Ploug, J. Bak, and E. A. Richter. 1992. Effects of glucose and insulin on development of impaired insulin action in muscle. Am. J. Physiol. 262:E440-E446.

42. Vuorinen-Markkola, H., V. A. Koivisto, and H. Yki-Jarvinen. 1992. Mechanisms of hyperglycemia-induced insulin resistance in whole body and skeletal muscle of type 1 diabetic patients. Diabetes. 41:571-580.

43. Balkan, B., and B. E. Dunning. 1994. Glucosamine inhibits glucokinase in vitro and produces a glucose-specific impairment of in vivo insulin secretion in rats. Diabetes. 43:1173-1179. 